Research Paper

\title{
Regulation of DMT1 on Bone Microstructure in Type 2 Diabetes
}

\author{
Wei-Lin Zhang', Hong-Zheng Meng', Mao-Wei Yang ${ }^{\bowtie}$ \\ Department of Orthopedics, the First Hospital of China Medical University, Shenyang, Liaoning, China \\ †These authors contribute equally to this work.
}

$\triangle$ Corresponding author: Mao-Wei Yang, Department of Orthopedics, The First Hospital of China Medical University, 155 North Nanjing Street, Shenyang, Liaoning, 110001, China. E-mail: ymw69@sohu.com; FAX: +86 24 83283360; Phone: +86 2483283360

(C) 2015 Ivyspring International Publisher. Reproduction is permitted for personal, noncommercial use, provided that the article is in whole, unmodified, and properly cited. See http://ivyspring.com/terms for terms and conditions.

Received: 2015.02.25; Accepted: 2015.05.18; Published: 2015.05.26

\begin{abstract}
Diabetic osteoporosis is gradually attracted people's attention. However, the process of bone microstructure changes in diabetic patients, and the exact mechanism of osteoblast iron overload are unclear. Therefore, the present study aimed to explore the function of DMT1 in the pathological process of diabetic osteoporosis. We build the type two diabetes osteoporosis models with SD rats and Belgrade rats, respectively. Difference expression of DMT1 was detected by using the method of immunohistochemistry and western blotting. Detection of bone microstructure and biomechanics and iron content for each group of samples. We found that DMT1 expression in type 2 diabetic rats was higher than that in normal rats. The bone biomechanical indices and bone microstructure in the rat model deficient in DMT1 was significantly better than that in the normal diabetic model. The loss of DMT1 can reduce the content of iron in bone. These findings indicate that DMT1 expression was enhanced in the bone tissue of type 2 diabetic rats, and plays an important role in the pathological process of diabetic osteoporosis. Moreover, DMT1 may be a potential therapeutic target for diabetic osteoporosis.
\end{abstract}

Key words: DMT1, type 2 diabetes, osteoporosis, biomechanics, micro-CT

\section{Introduction}

Due to economic developments, the incidence of chronic diseases such as diabetes is rising year by year. Various complications caused by diabetes significantly affect human health. A survey suggested that the risk of fractures in patients with diabetes is much higher than that in patients without diabetes[1]. A variety of complications in diabetics related to fractures affect the patient's quality of life and health, and result in a heavy economic burden and effects on society. Therefore, a study on the mechanism of diabetic bone microstructure changes is necessary to prevent fractures.

The relationship between iron overload and osteoporosis has previously been confirmed. Weiss G found excessive deposition of iron in patients with hemochromatosis, and 63\% of patients developed osteoporosis[2]. Chen B and other researchers found that iron overload had an inhibitory effect on osteogenesis[3]. However, the process of bone microstructure changes in diabetic patients, and the exact mechanism of osteoblast iron overload are unclear.

Divalent metal ion transporter 1 (DMT1) transports metal ions across membranes in mammals. The transporter is widely distributed in the human body. Studies have shown that DMT1 transports iron into epithelial cells in the intestinal membrane[4]. In Belgrade rats with DMT1 gene mutations, iron was not transferred into the cytoplasm, and the iron eventually returned to the cell surface, demonstrating that DMT1 is necessary for iron to be released into the cytoplasm[5].

The mechanism involved in bone microstructure changes in diabetes may be related to increased expression of DMT1in bone tissue, which promotes the 
release of iron ions from osteoblasts, causing iron overload in cells, leading to bone microstructure changes resulting in increased bone fragility and an increased risk of fracture. In the present study, Belgrade rats were used to verify the above hypothesis, which if confirmed will provide a new method way for studying the theory of diabetic osteoporosis, and provide potential therapeutic targets for the clinical treatment of osteoporosis.

\section{Materials and Methods}

The experimental design fully complies with the randomized controlled trial principle

\section{Ethics Statement}

The institutional Ethics Review Board of the First Hospital of China Medical University approved the study. The using of animal in our experiments is consistent with ethical requirements. All activities associated with this research project will be performed in accordance with the First Hospital of China Medical University Institutional Guidelines and Clinical Regulations.

\section{Experimental animals}

Male SPF SD rats, 3-months old, weighing 200 \pm $20 \mathrm{~g}$ were purchased from China Medical University, Department of Experimental Animals(Animal Certificate Number: SCXK (Liaoning) 2008-0005). Male Belgrade rats, the Belgrade rat is an animal model of DMT1 deficiency, 3-months old, weighing 200 $20 \mathrm{~g}$ were purchased from the Rat Resource \& Research Center at the University of Missouri, USA. 20 SD rats (10 rats were used to establish a type 2 diabetes model and 10 used for comparison) were used to determine the differential expression of DMT1. 30 SD rats and 15 Belgrade rats (15 SD rats were used to establish a normal type 2 diabetes model group, 15 SD rats were included in the sham group, 15 Belgrade rats were used to establish a type 2 diabetes Belgrade model group) were included to determine the targets of biomechanics and bone microstructure.

\section{Models and specimen collection}

The rats received a high-fat diet for two months and were allowed water for 12 hours/day. The rats were given an intraperitoneal injection of streptozotocin (STZ) at a dose of $30 \mathrm{mg} / \mathrm{kg}$. After 72 hours, fasting plasma glucose $>7.8 \mathrm{mmol} /$ Land reduced insulin sensitivity were observed and the models were successfully established[6]. The rats not used for modeling were fed a normal diet. All rats were housed under standard laboratory conditions and maintained under controlled temperature $\left(22 \pm 3^{\circ} \mathrm{C}\right)$ and humidity conditions with a daily cycle of $12 \mathrm{~h}$ light and $12 \mathrm{~h}$ dark. The weight of the rats was maintained between $220 \mathrm{~g}$ and $270 \mathrm{~g}$, and blood glucose was maintained between $5 \mathrm{mmol} /$ Land $18 \mathrm{mmol} / \mathrm{L}$. Rats with values outside these ranges were eliminated. The rats were fed up to 8 months of age, killed by cervical dislocation, the tibia was immediately removed aseptically and placed into fresh $4 \%$ phosphate buffered formalin solution, and stored at $4^{\circ} \mathrm{C}$ in a refrigerator.

\section{Immunohistochemistry}

Tissue sections $(5 \mu \mathrm{m})$ were incubated with rabbit anti-rat DMT1 (1:800; Santa Cruz Biotechnology) primary antibody. Horseradish peroxidase-labeled goat anti-rabbit (1:400; Santa Cruz Biotechnology) secondary antibody was used. Semi-quantitative analysis was performed at $200 \times$ magnification per visual field $\left(0.145 \mathrm{~mm}^{2}\right)$ for DMT1 extravasation, using imaging software (ImagePro Plus 6.0; Media Cybernetics, Bethesda, MD, USA). The mean IOD values were analyzed and averaged. The semi quantitative analysis of immunohistochemical results on the basis of the positive cell percentage ratio and tinting strength. - and \pm judged as the negative, + and ++ judged as positive, the positive cells : $0 \%$ recorded as 0 points, $\leq 25 \%$ recorded as 1 points, $26-50 \%$ recorded as 2 points, $51-75 \%$ recorded as 3 points, $>75 \%$ recorded as 4 points. Coloring intensity: no color recorded as 0 points, Light yellow recorded as 1 point, Claybank recorded as 2 points, Brown recorded as 3 points. Two results are combined: 0 points for $(-), 2-3$ points for ( $\pm), 4-5$ points for $(+), 6-7$ points for $(++)$.

\section{Bone biomechanical test}

The rat tibias were analysis by Biomechanical properties with 858 Mini Bionix materials testing systems. The tibias were placed on rheometer three-point bending test, loading rate was $0.01 \mathrm{~mm} . \mathrm{s}^{-1}$, a span of $15 \mathrm{~mm}$. Amount of inner and outer middle backbone by the load, degree of conversion and draw radial stress-strain curve. We got maximum strength and elastic modulus through this curve.

\section{Micro-CT scan}

Fixed the handle good right distal femur (truncated) along the long axis perpendicular to the specimen in the sample holder, viva CT 40 to select scan parameters : image matrix of $1024 \times 1024$, Integration time (integration time) for $200 \mathrm{~ms}$, energy/intensity for $70 \mathrm{kVp}, 114 \mu \mathrm{A}, 8 \mathrm{~W}$. After the scan is complete, select from the distal growth plate $1.0 \mathrm{~mm}, 3.0 \mathrm{~mm}$ thickness of the bone tissue is interested in cancellous bone area (region of interest, ROI) line of reconstruction, the lowest threshold of 190 extracts image information. After recombinant images using Micro-CT comes with software for quantitative analysis. Physi- 
cal parameters as follows: bone mineral density (BMD), bone volume/total volume (BV/TV), trabecular number (Tb.N), trabecular thickness (Tb.Th).

\section{Haematoxylin and eosin (HE) staining}

Tissues were fixed in $4 \%$ paraformaldehyde/ phosphatebuffered saline (PBS), post-fixed with the same fixative and cut into $16 \mu \mathrm{m}$ sections on a freezing microtome. Standard HE staining was performed and degeneration grade was scored by two independent observers as previously reported[7].

\section{Western blotting}

Proteins of NP tissue and cultured cells were lysed by Lysis Buffer containing PMSF on ice. The extracted proteins were electrophoresed through $12 \%$ SDS polyacrylamide gels and transferred to a PVDF membrane (Invitrogen). After being blocked in PBS containing $5 \%$ fat-free milk powder for $1 \mathrm{~h}$, antibodies against DMT1 (Abcam, Cambridge, MA,USA) were used to detect the proteins. Goat anti-rabbit immunoglobulin conjugated to horseradish peroxidase (Sigma, St. Louis, MO, USA) was used as the secondary antibody. Signals were detected using Pierce ECL western blotting substrate (Pierce Biotechnology, Rockford, CA, USA).

\section{Tibia detect iron content}

The tibia dried to constant weight, referred to the dry weight, is placed $650^{\circ} \mathrm{Ccalcined}$ to the powder in a muffle furnace, grind with a mortar sufficiently Pieces, accurately weighed sample taken post-ash $0.05 \mathrm{~g}$, was added into $1 \mathrm{~mL} 1: 1 \mathrm{HNO}_{3}, 0.2 \mathrm{~mL} \mathrm{1:} 1 \mathrm{HCl}$ solution a mixed solution of Solution with ultrapure water (18.2 megohms) volume to $10 \mathrm{~mL}$, and then fully dissolve ultrasound to translucent, in inductively coupled plasma Daughter emission spectrometer (ICP-AES, the US Perkin Elmer Corporation, Model : Optima 2100DV) adopted on Determination of iron content by atomic absorption spectrometry.

\section{Plasma measurements}

Venous blood (tail vein) was collected before experimentation to measure fasting concentrations of blood glucose (FBG) (Roach blood glucose instrument). Intraocular angular vein blood $(2.5-4 \mathrm{~mL})$ was collected for measurement of fasting plasma insulin (FINS) by radioimmunoassay (3v-diagnostic Bioengineer, Shandong, China) and plasma estrogen by ELISA (Rat Estrogen/E ELISA Kit, 3v-Diagnostic Bioengineer, Shandong, China). The insulin sensitivity index (ISI) was calculated using the formula (1/FBG $\times$ FINS)[8].

\section{Statistical analysis}

Two-group comparisons were performed using
Student's t-test. Multiple group parameters comparisons were performed using one-way analysis of variance followed by Turkey's post-test. A P value less than 0.05 was considered statistically significant. The statistical analysis was performed using the SPSS statistical package (SPSS, Chicago, IL, USA).

\section{Results}

\section{Correlation between DMT1 and diabetic osteoporosis}

The tibias removed from SD rats which were used as a model of type II diabetic osteoporosis were analyzed by immunohistochemistry and western blotting. The expression level of DMT1 in the type 2 diabetic osteoporosis model was found to be higher than that in normal rats (Figure 1).

\section{Evaluation of the type 2 diabetic osteoporosis model}

Fasting plasma glucose and fasting plasma insulin were determined in each group of rats, and the insulin sensitivity index (ISI) was calculated. We found that the normal model group and the Belgrade model group conformed to the standard, and were regarded as successful models (Figure 2, Table 1).

Table 1. Each group of data

\begin{tabular}{|l|l|l|l|}
\hline & sham & normal & belgrade \\
\hline BMD $\left(\mathrm{g} / \mathrm{cm}^{2}\right)$ & $0.277 \pm 0.010$ & $0.207 \pm 0.017$ & $0.245 \pm 0.004$ \\
\hline Iron content $(\mu \mathrm{g} / \mathrm{g})$ & $79.230 \pm 10.200$ & $150.230 \pm 11.500$ & $65.510 \pm 13.600$ \\
\hline MaxStrength $(\mathrm{MPa})$ & $139.900 \pm 12.000$ & $106.100 \pm 9.800$ & $122.500 \pm 10.300$ \\
\hline $\begin{array}{l}\text { ElasticModulus } \\
(\mathrm{KPa})\end{array}$ & $5.460 \pm 1.000$ & $5.310 \pm 0.800$ & $5.030 \pm 0.600$ \\
\hline Tb.N $\left(\mathrm{cm}^{-1}\right)$ & $25.100 \pm 1.400$ & $19.100 \pm 2.600$ & $22.210 \pm 1.600$ \\
\hline $\mathrm{BV} / \mathrm{TV}(\%)$ & $44.400 \pm 5.300$ & $23.300 \pm 5.200$ & $33.300 \pm 5.200$ \\
\hline Tb.Th $\left(\mathrm{cm}^{-1}\right)$ & $1.770 \pm 0.200$ & $1.210 \pm 0.100$ & $1.520 \pm 0.150$ \\
\hline FINS $(\mathrm{U} / \mathrm{L})$ & $23.5400 \pm 12.200$ & $79.300 \pm 17.000$ & $80.000 \pm 15.000$ \\
\hline FBG $(\mathrm{mmol} / \mathrm{L})$ & $4.300 \pm 15.000$ & $8.300 \pm 2.000$ & $8.500 \pm 1.600$ \\
\hline
\end{tabular}

\section{Effects of DMTI on bone mineral density and iron content}

The bone mineral density and iron content in each rat tibia were determined. We found that the bone mineral density in the Belgrade model group and normal model group was lower than that in the sham group. However, bone mineral density in the Belgrade model group was higher than that in the normal model group. The iron content in the normal model group was higher than that in the sham group, and the iron content in the Belgrade model group was lower than that in the sham group (Figure 3, Table 1).

\section{Effects of DMT1 on bone microstructure}

The rat tibias were scanned and analyzed using micro-CT. Bone microstructure in the Belgrade model 
group was better than that in the normal model group, however, bone microstructure in both model groups was worse than that in the sham group. The results of HE staining confirmed these findings (Figure 4,5 , Table 1 ).

\section{Effects of DMTI on bone biomechanics}

Using the MaxStrength and ElasticModulus tests on the tibia from each group of rats, we found that bone biomechanics in the Belgrade model group was better than those in the normal model group, but the two groups were worse in terms of the MaxStrength indices than the sham group. However, no statistical differences of in the ElasticModulus test were observed between the groups (Figure 6, Table 1).

\section{Discussion}

In the type 2 diabetes Belgrade rat model, we determined the function of DMT1 in diabetic osteoporosis, and found the following: (1) DMT1 expression in type 2 diabetic rats was higher than that in normal rats. (2) The bone biomechanical indices in the rat model deficient in DMT1 were significantly better than those in the normal diabetic model.(3) Bone microstructure in the rat model deficient in DMT1 was significantly better than that in the normal diabetic model. (4) The loss of DMT1 can reduce the content of iron in bone.

A

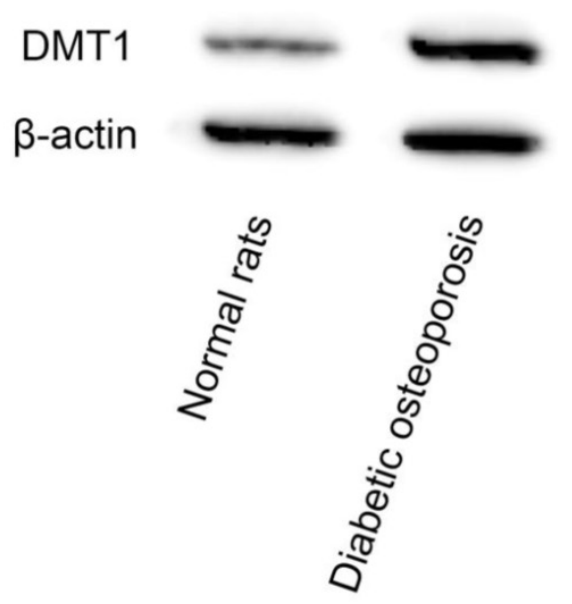

B
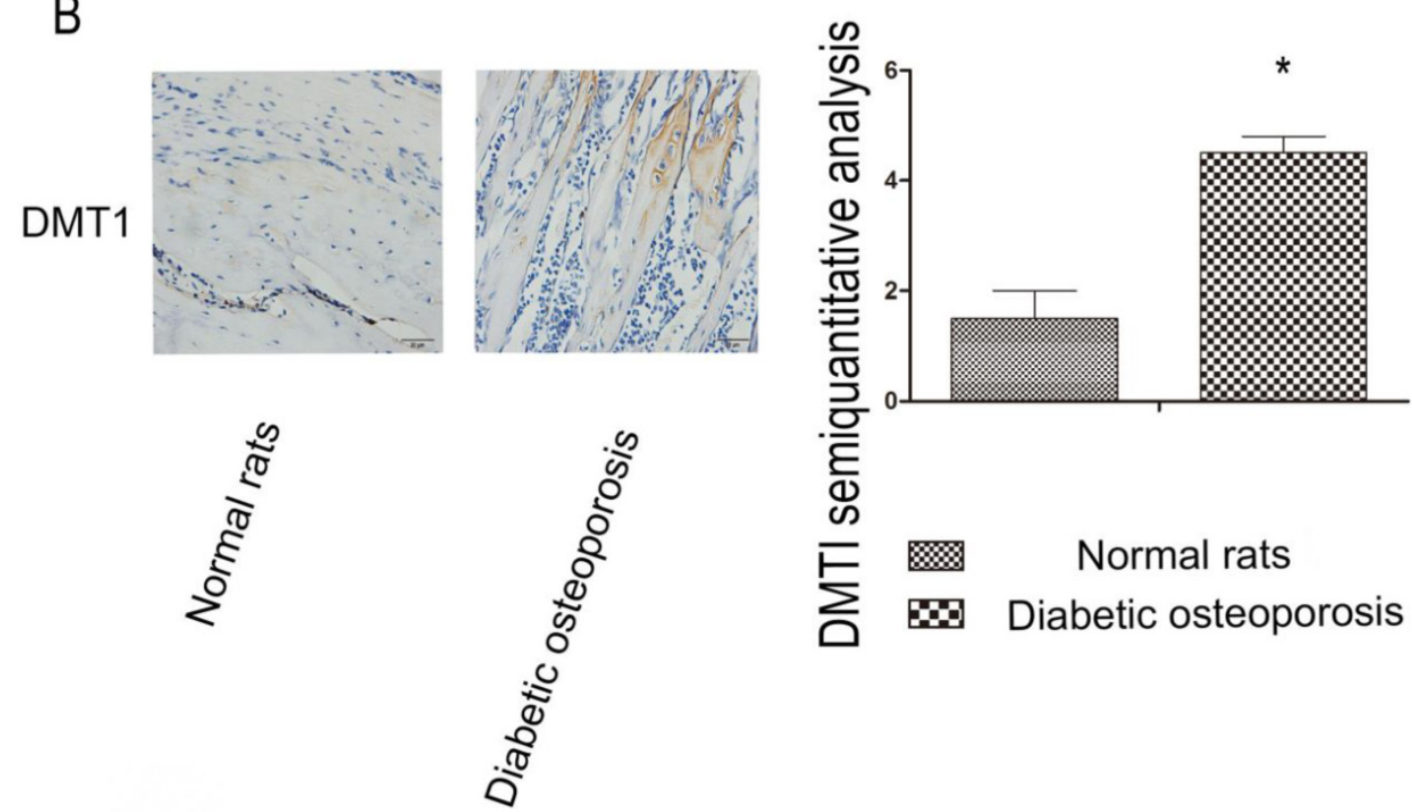

Figure 1. Correlation between DMT1 and diabetic osteoporosis. (A) Western blot analysis shows expression of DMT1 in diabetic osteoporosis group is stronger than normal rats group. (B) The situation of DMT1 expression in bone tissue using immunohistochemical method. Diabetic osteoporosis group significantly was stronger than normal rats group. Scale bars, $20 \mu \mathrm{m} . \mathrm{n}=10$ per group. Data are means \pm SD. $* \mathrm{P}<0.05$. 

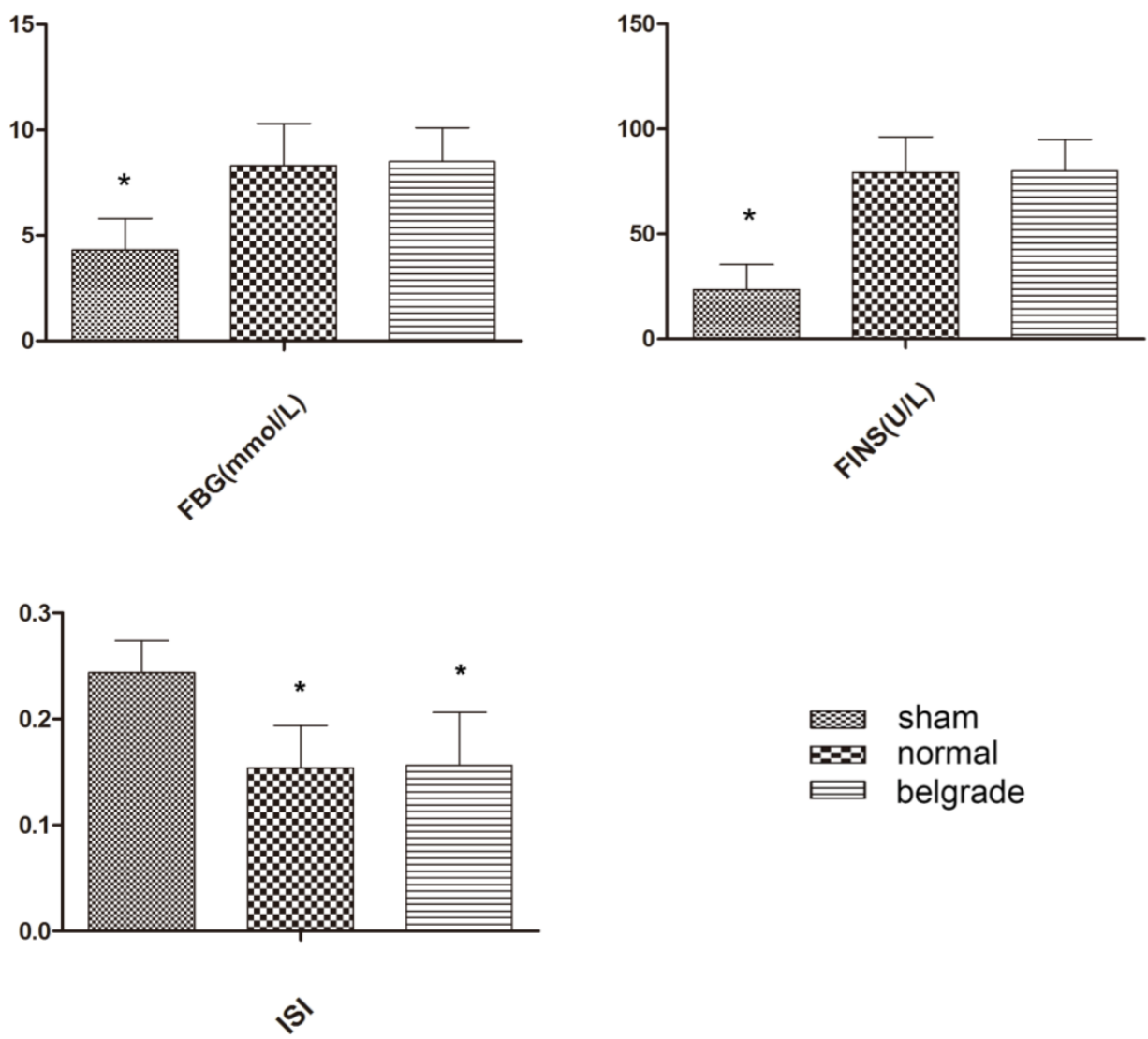

Figure 2. Evaluation of the type 2 diabetic osteoporosis model. No significant difference between Belgrade model group and normal model group, but compared with sham group had significant difference, $n=10$ per group. Data are means $\pm S D$. $* P<0.05$.

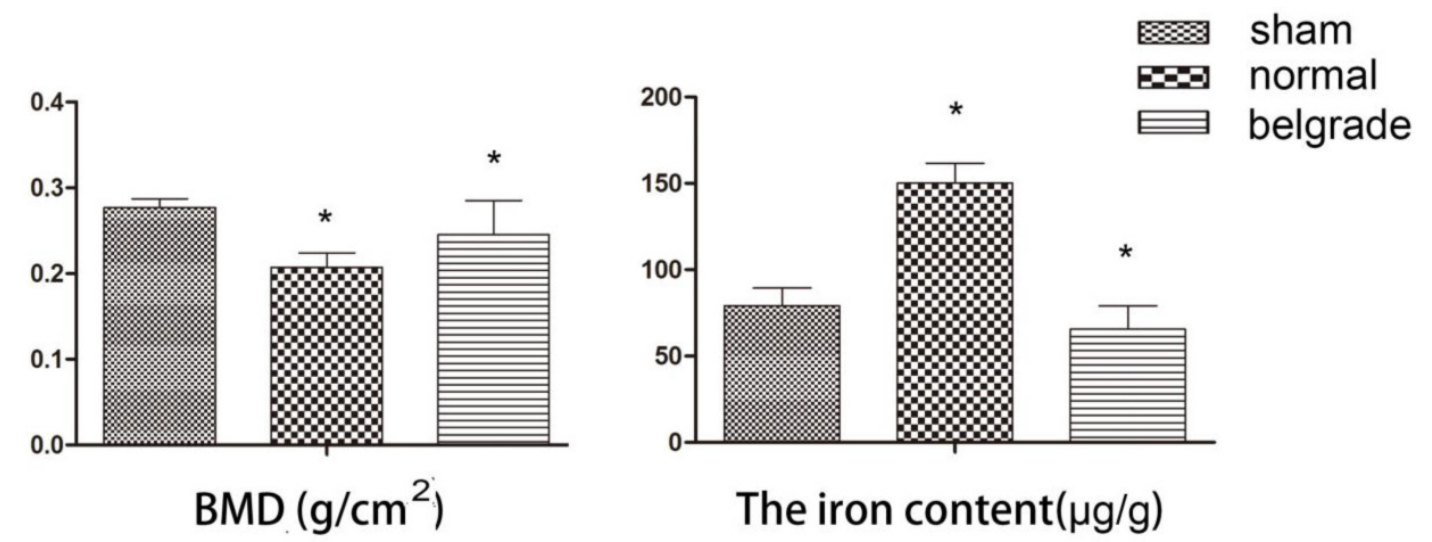

Figure 3. Effects of DMT1 on bone mineral density and iron content. There were statistically significant differences between the each group. The bone mineral density of Belgrade model group was higher than normal model group, but the two groups were lower than those in sham group. Iron content of Belgrade model group was the lowest. Iron content of normal model group was the highest, $n=10$ per group. Data are means $\pm S D$. $* P<0.05$. 
HE

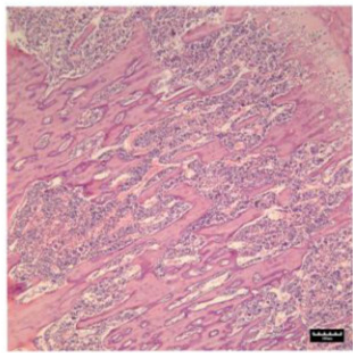

sham

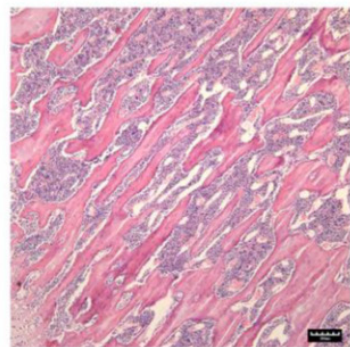

belgrade

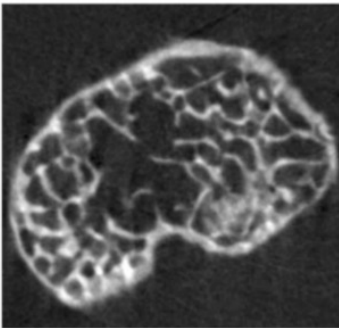

sham

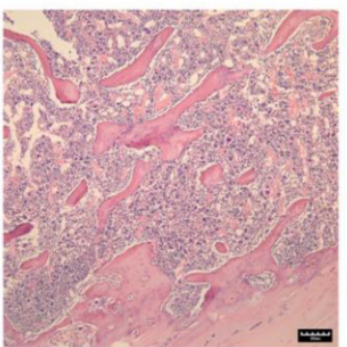

normal

micro-CT

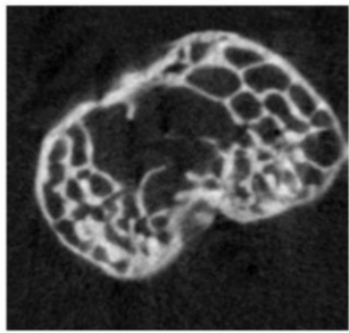

normal

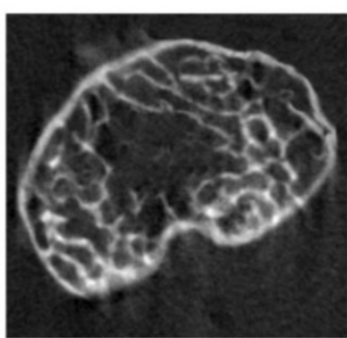

belgrade

Figure 4. Effects of DMTI on bone microstructure. Through the HE staining we observed the number and thickness of trabecular bone. Belgrade model group was better than normal model group, but the two groups were worse than those in sham group. This result can also be verified by micro-CT image. Scale bars, $100 \mu \mathrm{m}$.

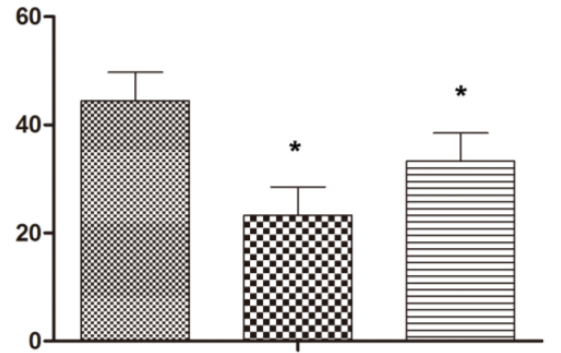

8 sit $^{0010}$

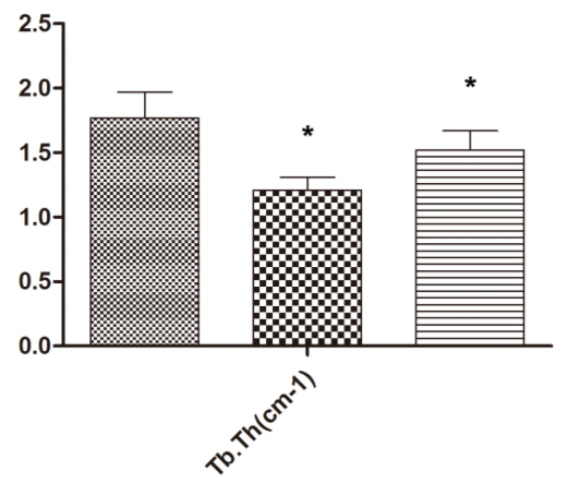

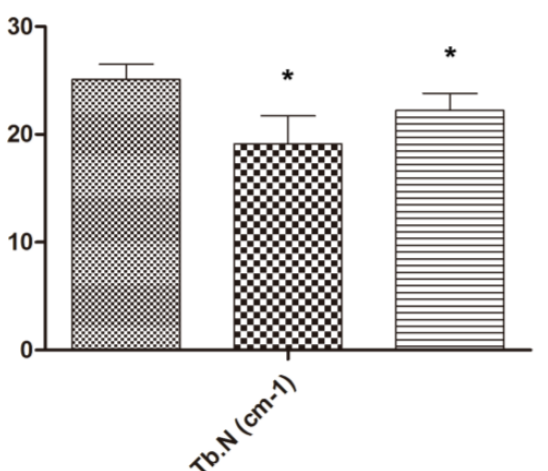

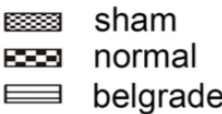

Figure 5. Effects of DMT1 on bone microstructure. According to the results of BV/TV, Tb.N, Tb.Th, Belgrade model group was better than normal model group, but the two groups were worse than those in sham group, $n=10$ per group. Data are means \pm SD. $* P<0.05$. 


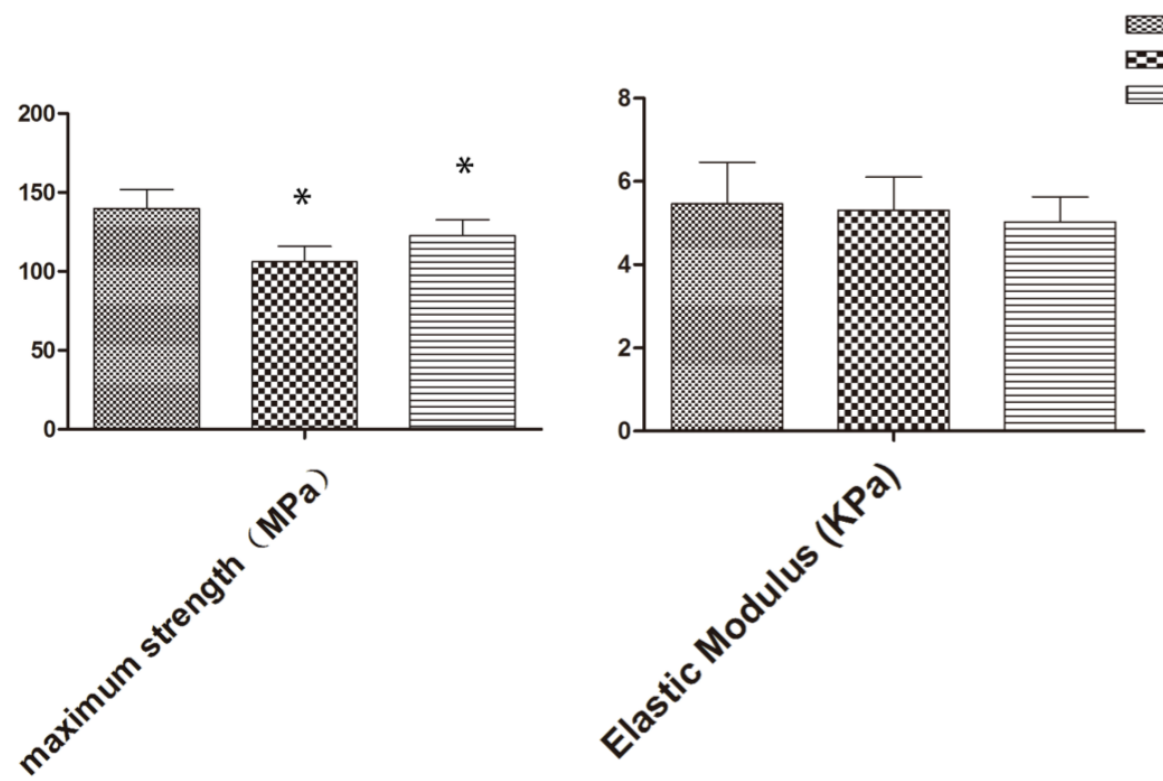

Figure 6. Effects of DMT1 on bone biomechanics. According to the results of MaxStrength and ElasticModulus tests, Belgrade model group was better than normal model group, but the two groups were worse than those in sham group, $n=10$ per group. Data are means $\pm S D$. $* P<0.05$.

Diabetic osteoporosis belongs to secondary osteoporosis, which is a serious diabetes complications in human skeletal system, the concept was first proposed in 1948[9]. It has recently become apparent that the risk of osteoporosis-related bone fracture is increased in both type 1 and type 2 diabetic patients[10, 11]. Type 1 diabetes is generally associated with a reduction in BMD, but the change of BMD in type 2 diabetic osteoporosis are not obvious [12], so the pathogenesis of osteoporosis in type 2 diabetes compared with type 1 diabetes osteoporosis is more complex, and the incidence of type 2 diabetes is higher than the incidence of type 1 diabetes, so this study focuses on type 2 diabetes.

When the binding capacity of transferritin is overwhelmed by a high iron concentration in the circulation and tissues, free iron is deposited in tissues and thus creates a pathological condition called iron overload[13]. Existing research shows that iron overload is associated with many diseases, such as hemochromatosis, sickle cell disease, and liver diseases[14-16]. However, research has also suggested that iron overload is associated with bone metabolism abnormalities, such as osteopenia, osteoporosis, and osteomalacia[17-20]. However, the mechanism of iron overload in osteoporosis has not been extensively studied. The present study, for the first time, showed a difference in DMT1 expression between diabetic rats and normal rats. This discovery is of great significance in determining the mechanism of iron overload.

DMT1 is the major apical transporter responsible for intestinal $\mathrm{Fe}^{2+}$ absorption, and is also ubiquitously expressed in the endosomalcompartments where it is responsible for $\mathrm{Fe}^{2+}$ export from the endosome during the transferrin cycle[21, 22]. Thus, DMT1 expression is closely related to iron overload. DMT1 is not only involved in iron and manganese metabolism, but is also involved in the uptake of other metals. Research has shown that DMT1 also participates in $\mathrm{Cu}^{2+}$ and $\mathrm{Cd}^{2+}$ transport[23, 24]. Due to the characteristics of DMT1, there are currently many research studies being carried out. However, to date, there is no relevant research on the relationship between DMT1 and osteoporosis. For the first time, we found that DMT1 affects the biological characteristics of bone and bone microstructure. And we confirmed the effect of DMT1 on iron content in bone tissue. This discovery has highlighted the important role of DMT1 in the process of osteoporosis.

Belgrade rats were described for the first time in 1966 and were the offspring of an X-irradiated albino rat in Belgrade, Yugoslavia[25]. The Belgrade rat is an animal model of DMT1deficiency.This deficiency is due to a glycine-to-arginine substitution (G185R) in the fourth putative transmembranedomain of DMT1 resulting in loss of activity of the transporter[26]. There are multiple examples where the Belgrade rat, as a model of iron deficiency, has been useful in characterizing not only the role of DMT1 in the transport of this metal, but also its contribution to pathologies of intermediary metabolism, its protective role in detoxification of the lungs, its participation in neurotoxicity of airborne metal uptake by the olfactory pathway, in the development of the kidneys, in promoting altered renal function, in brain iron metabolism and in hepatic iron handling[27-29]. How- 
ever, the reason why these rats were chosen for this study was due to their stable lack of DMT1. In addition, interference and individual differences are small, and these rats have many other advantages. This study is the first to establish a diabetic osteoporosis model using Belgrade rats. This is of significant importance in the study of DMT1 and osteoporosis.

Laboratory animals have played a key role in the unprecedented recent improvements in the management of osteoporosis. Animal models of osteoporosis involve a variety of animals and a variety of methods. Each model has its own advantages, disadvantages and scope of use[30, 31]. This study used a rat model of diabetes mellitus combined with osteoporosis established using intralipid and a small dose of streptozotocin. Because our research goal was to explore the mechanism of type 2 diabetes complicated by osteoporosis, the model needed to imitate the pathological process of type 2 diabetes. This model was helpful in our study. Three-month old rats are sexually mature, 6-monthold rats have mature bones, and 17-month old rats are relatively old[32]. We used 8 -monthold rats, as the rat bones were fully mature and completely affected by diabetes. The bone characteristics of these rats sufficiently reflected the effects of the differential expression of DMT1. Type 1 diabetes is the absolute lack of insulin, and the main characteristic of type 2 diabetes is insulin resistance. We tested the ISI in order to assess whether this model is type 2 diabetes model.

There are several limitations in the present study. For example, although our data demonstrated the relationship between DMT1 and osteoporosis, we did not perform in vitro experiments. This study focused on the effects of DMT1 on diabetic osteoporosis, which has laid the foundation to explore the specific mechanism involved and indicate the direction for future research. Further in-depth studies on this topic are required.

In conclusion, DMT1 expression was enhanced in the bone tissue of type 2 diabetic rats, and plays an important role in the pathological process of diabetic osteoporosis. Moreover, DMT1 may be a potential therapeutic target for diabetic osteoporosis.

\section{Acknowledgement}

This study was supported by the Chinese National Natural Science Foundation Project, Fund of liaoning province department of education and Shenyang municipal science and technology fund (81471094, 81170808, L2013301 and F12-277-1-47).

\section{Author Contributions}

WLZ, HZM, MWY conceived of the study, participated in the design of the study and performed the statistical analyses. All authors carried out the experiments. WLZ drafted the manuscript with the help of HZM and YMW. All authors have read and approved the final manuscript

\section{Competing Interests}

The authors declare no competing financial interests.

\section{References}

1. Jepsen KJ, Schlecht SH. Biomechanical mechanisms: resolving the apparent conundrum of why individuals with type II diabetes show increased fracture incidence despite having normal BMD. Journal of bone and mineral research : the official journal of the American Society for Bone and Mineral Research. 2014; 29: 784-6. doi:10.1002/jbmr.2189.

2. Weiss G. Genetic mechanisms and modifying factors in hereditary hemochromatosis. Nature reviews Gastroenterology \& hepatology. 2010; 7: 50-8. doi:10.1038/nrgastro.2009.201.

3. Chen B, Yan YL, Liu C, Bo L, Li GF, Wang H, et al. Therapeutic effect of deferoxamine on iron overload-induced inhibition of osteogenesis in a zebrafish model. Calcified tissue international. 2014; 94: 353-60. doi:10.1007/s00223-013-9817-4.

4. Andrews NC, Schmidt PJ. Iron homeostasis. Annual review of physiology. 2007; 69: 69-85. doi:10.1146/annurev.physiol.69.031905.164337.

5. Sheftel AD, Mason AB, Ponka P. The long history of iron in the Universe and in health and disease. Biochimica et biophysica acta. 2012; 1820: 161-87. doi:10.1016/j.bbagen.2011.08.002.

6. Li B, Wang Y, Liu Y, Ma J, Li Y. Altered gene expression involved in insulin signaling pathway in type II diabetic osteoporosis rats model. Endocrine. 2013; 43: 136-46. doi:10.1007/s12020-012-9757-1.

7. Sive JI, Baird P, Jeziorsk M, Watkins A, Hoyland JA, Freemont AJ. Expression of chondrocyte markers by cells of normal and degenerate intervertebral discs. Molecular pathology : MP. 2002; 55: 91-7.

8. Vangipurapu J, Stancakova A, Kuulasmaa T, Soininen P, Kangas AJ, Ala-Korpela M, et al. Association between liver insulin resistance and cardiovascular risk factors. Journal of internal medicine. 2012; 272: 402-8. doi:10.1111/j.1365-2796.2012.02540.x.

9. Takamoto I, Kadowaki T. [Diabetes and osteoporosis]. Clinical calcium. 2004; 14: 255-61. doi:CliCa0402255261.

10. Merlotti D, Gennari L, Dotta F, Lauro D, Nuti R. Mechanisms of impaired bone strength in type 1 and 2 diabetes. Nutrition, metabolism, and cardiovascular diseases : NMCD. 2010; 20: 683-90. doi:10.1016/j.numecd.2010.07.008.

11. Vestergaard P. Discrepancies in bone mineral density and fracture risk in patients with type 1 and type 2 diabetes--a meta-analysis. Osteoporosis international : a journal established as result of cooperation between the European Foundation for Osteoporosis and the National Osteoporosis Foundation of the USA. 2007; 18: 427-44. doi:10.1007/s00198-006-0253-4.

12. Dominguez LJ, Muratore M, Quarta E, Zagone G, Barbagallo M. [Osteoporosis and diabetes]. Reumatismo. 2004; 56: 235-41.

13. Li GF, Pan YZ, Sirois P, Li K, Xu YJ. Iron homeostasis in osteoporosis and its clinical implications. Osteoporosis international : a journal established as result of cooperation between the European Foundation for Osteoporosis and the National Osteoporosis Foundation of the USA. 2012; 23: 2403-8. doi:10.1007/s00198-012-1982-1.

14. Guggenbuhl P, Fergelot P, Doyard M, Libouban H, Roth MP, Gallois Y, et al. Bone status in a mouse model of genetic hemochromatosis. Osteoporosis international : a journal established as result of cooperation between the European Foundation for Osteoporosis and the National Osteoporosis Foundation of the USA. 2011; 22: 2313-9. doi:10.1007/s00198-010-1456-2.

15. Sarrai M, Duroseau H, D'Augustine J, Moktan S, Bellevue R. Bone mass density in adults with sickle cell disease. British journal of haematology. 2007; 136: 666-72. doi:10.1111/j.1365-2141.2006.06487.x

16. Wibaux C, Legroux-Gerot I, Dharancy S, Boleslawski E, Declerck N, Canva V, et al. Assessing bone status in patients awaiting liver transplantation. Joint, bone, spine : revue du rhumatisme. 2011; 78: 387-91. doi:10.1016/j.jbspin.2011.03.001.

17. Guggenbuhl P, Deugnier Y, Boisdet JF, Rolland Y, Perdriger A, Pawlotsky Y, et al. Bone mineral density in men with genetic hemochromatosis and HFE gene mutation. Osteoporosis international : a journal established as result of cooperation between the European Foundation for Osteoporosis and the National Osteoporosis Foundation of the USA. 2005; 16: 1809-14. doi:10.1007/s00198-005-1934-0.

18. Isomura $H$, Fujie $K$, Shibata $K$, Inoue $N$, Iizuka $T$, Takebe $G$, et al. Bone metabolism and oxidative stress in postmenopausal rats with iron overload. Toxicology. 2004; 197: 93-100. doi:10.1016/j.tox.2003.12.006

19. Mahachoklertwattana P, Sirikulchayanonta V, Chuansumrit A, Karnsombat P, Choubtum L, Sriphrapradang A, et al. Bone histomorphometry in children and adolescents with beta-thalassemia disease: iron-associated focal 
osteomalacia. The Journal of clinical endocrinology and metabolism. 2003; 88: 3966-72. doi:10.1210/jc.2002-021548.

20. Matsushima S, Hoshimoto M, Torii M, Ozaki K, Narama I. Iron lactate-induced osteopenia in male Sprague-Dawley rats. Toxicologic pathology. 2001; 29: 623-9.

21. Fleming MD, Romano MA, Su MA, Garrick LM, Garrick MD, Andrews NC. Nramp2 is mutated in the anemic Belgrade (b) rat: evidence of a role for Nramp2 in endosomal iron transport. Proceedings of the National Academy of Sciences of the United States of America. 1998; 95: 1148-53.

22. Gunshin H, Mackenzie B, Berger UV, Gunshin Y, Romero MF, Boron WF, et al. Cloning and characterization of a mammalian proton-coupled metal-ion transporter. Nature. 1997; 388: 482-8. doi:10.1038/41343.

23. Illing AC, Shawki A, Cunningham CL, Mackenzie B. Substrate profile and metal-ion selectivity of human divalent metal-ion transporter-1. The Journal of biological chemistry. 2012; 287: 30485-96. doi:10.1074/jbc.M112.364208.

24. Jiang L, Ranganathan $\mathrm{P}, \mathrm{Lu} \mathrm{Y}$, Kim C, Collins JF. Exploration of the copper-related compensatory response in the Belgrade rat model of genetic iron deficiency. American journal of physiology Gastrointestinal and liver physiology. 2011; 301: G877-86. doi:10.1152/ajpgi.00261.2011.

25. Sladic-Simic D, Zivkovic N, Pavic D, Marinkovic D, Martinovic J, Martinovitch PN. Hereditary hypochromic microcytic anemia in the laboratory rat. Genetics. 1966; 53: 1079-89.

26. Fleming MD, Trenor CC, 3rd, Su MA, Foernzler D, Beier DR, Dietrich WF, et al. Microcytic anaemia mice have a mutation in Nramp2, a candidate iron transporter gene. Nature genetics. 1997; 16: 383-6. doi:10.1038/ng0897-383.

27. Ferguson CJ, Wareing M, Delannoy M, Fenton R, McLarnon SJ, Ashton N, et al. Iron handling and gene expression of the divalent metal transporter, DMT1, in the kidney of the anemic Belgrade (b) rat. Kidney international. 2003; 64: 1755-64. doi:10.1046/j.1523-1755.2003.00274.x.

28. Thompson K, Molina RM, Brain JD, Wessling-Resnick M. Belgrade rats display liver iron loading. The Journal of nutrition. 2006; 136: 3010-4.

29. Thompson K, Molina RM, Donaghey T, Brain JD, Wessling-Resnick M. Iron absorption by Belgrade rat pups during lactation. American journal of physiology Gastrointestinal and liver physiology. 2007; 293: G640-4. doi:10.1152/ajpgi.00153.2007.

30. Lelovas PP, Xanthos TT, Thoma SE, Lyritis GP, Dontas IA. The laboratory rat as an animal model for osteoporosis research. Comparative medicine. 2008; 58 : 424-30.

31. Turner RT, Maran A, Lotinun S, Hefferan T, Evans GL, Zhang M, et al. Animal models for osteoporosis. Reviews in endocrine \& metabolic disorders. 2001; 2: $117-27$

32. Luippold G, Klein T, Mark M, Grempler R. Empagliflozin, a novel potent and selective SGLT-2 inhibitor, improves glycaemic control alone and in combination with insulin in streptozotocin-induced diabetic rats, a model of type 1 diabetes mellitus. Diabetes, obesity \& metabolism. 2012; 14: 601-7. doi:10.1111/j.1463-1326.2012.01569.x. 